\title{
Pre-Eruptive Coronal Resorption and Congenitally Missing Teeth in a Patient with Amelogenesis Imperfecta: A Case Report
}

\author{
Ozkan Miloglua \\ Osman Fatih Karaalioglub \\ Fatma Caglayan ${ }^{a}$ \\ Zeynep Duymus Yesilc
}

\begin{abstract}
This clinical report describes a male with autosomal recessive generalized hypoplastic amelogenesis imperfecta. This case is unusual in coronal resorptions prior to tooth eruption. This finding has been reported in some cases of autosomal recessive, autosomal dominant and X linked amelogenesis imperfecta (Al). In reported cases, the defects were usually small and occurred in a maximum of 2 teeth per person. In our case, pre-eruptive coronal resorptions affected three second molar teeth from both jaws. On the other hand; congenitally missing teeth and malocclusion were present in this case. Recall evaluations at 3 month intervals occurred for a period of 2 years and then prosthodontic management began. (Eur J Dent 2009;3:140-144)
\end{abstract}

Key words: Amelogenesis imperfecta; Congenital missing teeth; Pre-eruptive coronal resorption; Malocclusion; Prosthetic restoration.

\section{INTRODUCTION}

Amelogenesis imperfecta (Al) is a developmental, often inherited disorder affecting dental enamel. It usually occurs in the absence of systemic features

a Research Assistant, Ataturk University, Faculty of Dentistry, Department of Oral Diagnosis and Radiology, Erzurum, Turkey.

b Research Assistant, Ataturk University, Faculty of Dentistry, Department of Prosthodontics, Erzurum, Turkey.

c Professor, Ataturk University, Faculty of Dentistry, Department of Prosthodontics, Erzurum, Turkey.

- Corresponding author: Dt. Ozkan Miloglu Atatürk University, Faculty of Dentistry, Department of Oral Diagnosis and Oral Radiology, 25240, Erzurum, Turkey.

Fax: +90 4422360945 E-mail: omilogluahotmail.com

and comprises diverse phenotypic entities. ${ }^{1} \mathrm{Al}$ has an estimated prevalence of approximately between 1:8000 and 1:700. ${ }^{2}$ As in hereditary disorder, clustering in certain geographic areas may occur, resulting in a wide range of reported prevalence. In general, both the deciduous and permanent dentitions are diffusely involved. .,4 $^{3}$

Although $\mathrm{Al}$ is considered to primarily affect the enamel, further alterations could include unerupted teeth, ${ }^{1,4-8}$ congenitally missing teeth, ${ }^{4,8}$ taurodontism, 1,4,6,7,9,10 pulpal calcifications, $1,5,6,11$ crown and root resorption, ${ }^{1,4-6,8}$ cementum deposition, ${ }^{5,6}$ truncated roots, ${ }^{6}$ dental and skeletal open bite, ${ }^{6,12}$ interradicular dentinal dysplasia, ${ }^{6,7}$ gingival hyperplasia ${ }^{5,8}$ and follicular hyperplasia. ${ }^{6}$ 
As mentioned above, additional dental pathologies such as eruption failure accompanying amelogenesis imperfecta and crown resorptions, may be in question. In literature reports, crown resorption in pre-eruptive teeth has been demonstrated in one or a few teeth at maximum. This article presents a male with generalized hypoplastic amelogenesis imperfecta, who has crown resorptions in multiple pre-eruptive teeth accompanying congenital tooth loss.

\section{CASE REPORT}

20 years old male patient referred to the Department of Prosthodontic Dentistry in Ataturk University for aesthetic and tooth sensitivity complaints. His medical history and general physical condition were unremarkable. His hair, skin, and nails appeared normal. The pregnancy and the post-natal period had been uneventful. Patient's parents were examined and showed unaffected permanent dentitions. No evidence of a similar condition could be elicited in the family

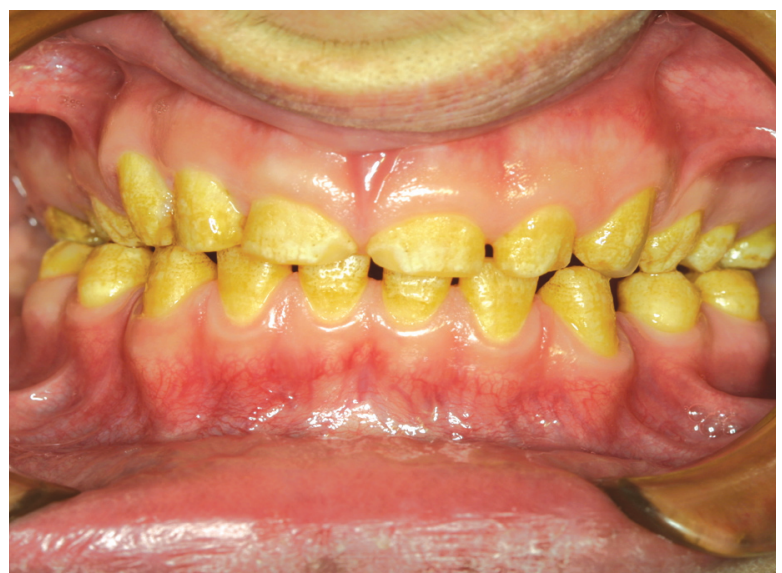

Figure 1. Pretreatment view of teeth in occlusion. history. The patient lived in a non-fluoridated area and had never taken fluoride supplements. Clinically, the permanent teeth were yellowish in color with a rough enamel surface as a result of mild hypoplasia. The incisal edges were thin and the teeth were widely spaced (Figure 1). Both upper second molars and lower first and second molars were clinically not visible. A general enlargement of the gingival tissues was not diagnosed but periodontal pockets were detected on the adjacent fully erupted teeth. Because of poor oral hygiene, presence of plaque accumulation and related chronic marginal gingivitis was in question.

The panoramic radiograph obtained at the referral showed permanent dentition which was affected by multiple intracoronal radiolucencies in both upper second molars and lower right second molar. Whereas, the defects of the both upper second molars were limited to enamel and dentin; in the lower right second molar the lesion involved the pulp chamber (Figure 2). The clinical examination of the patient revealed that the soft tissues overlying the unerupted affected teeth were intact. Lower left first and second molars were congenitally missing. Lower right first molar tooth was surgically removed and a residual mesial root was visible in radiography. Upper left third molar was congenitally missing, upper and lower third molars were present but unerupted. The contrast between enamel and dentin was normal and all teeth were affected from some degree of taurodontism but pulp stones were not visible in radiography. In recall evaluation after 1 year, no changes were determined in preeruptive resorption of second molars and in eruption of

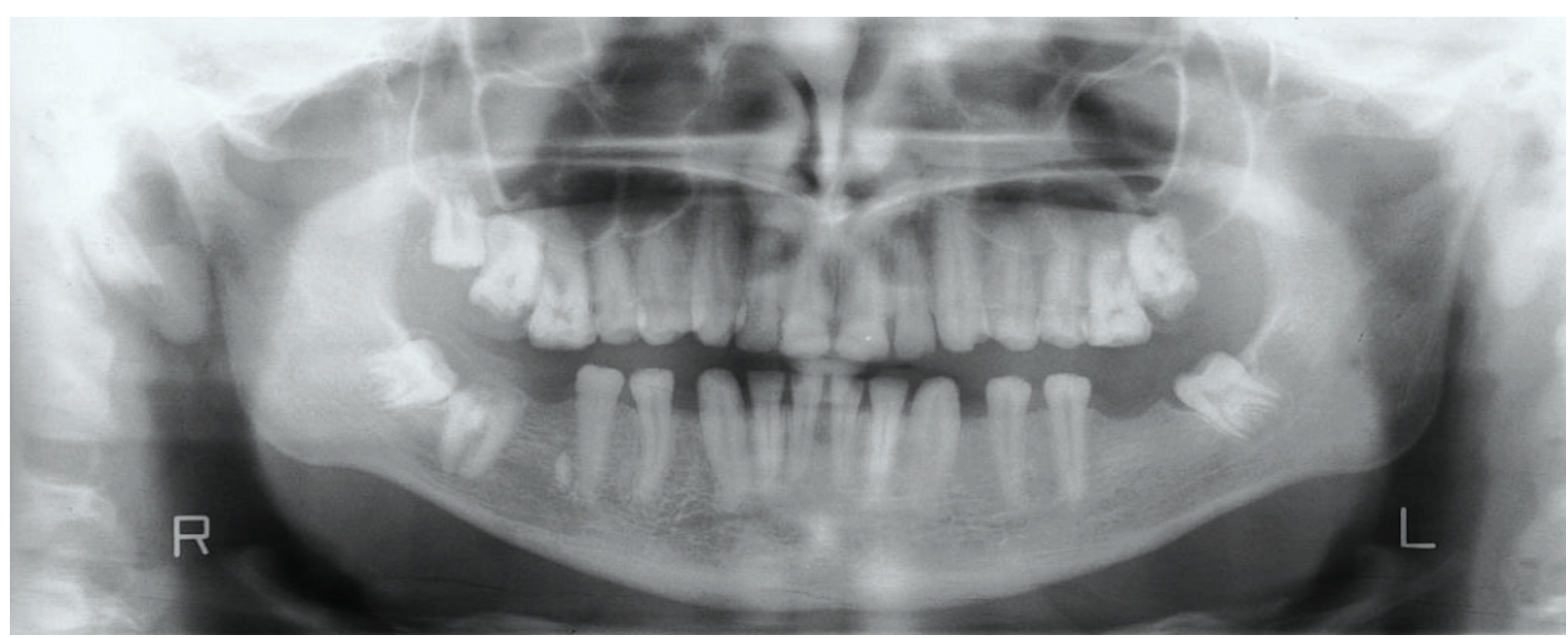

Figure 2. Panoramic radiograph of the patient at the first referral. 
third molars (Figure 3). Upper right first molar and upper left canine were restored due to caries lesion and lower right second molar was extracted.

All teeth had small clinical crowns and axial angle of the teeth were not prepared ideally of $3-6^{\circ}$ angle because of the teeth morphology; fullarch fixed denture were planned considering the retention of the denture after cementation.

Maxillary and mandibular anterior and posterior teeth were prepared for metal-ceramic restorations with narrow champher finish lines. Laboratory-processed provisional restorations were fabricated at an increased occlusal vertical dimension $(3.0 \mathrm{~mm})$, lined with methyl methacrylate acrylic resin (Major C\&B-V Dentine, Major, Moncalieri, Italyl and cemented with zincoxide eugenol (Temp-Bond; Kerr Corp). The patient used the provisional restorations at the newly established occlusal vertical dimension for 6 months without complications. Final impressions of the prepared maxillary and mandibular anterior teeth were obtained using vinyl polysiloxane impression material (Elite H-D; Zhermack). Working casts were generated from Type IV die stone (Bego Bremer Goldschlagerei Herbst GMBH Germany, 6124166) and mounted onto the articulator (Hager \& Werken, Duisburg, Germany) using interocclusal records. Full arch metalceramic fixed denture (Ivoclar Vivadent) replacing teeth were fabricated, evaluated intraorally, adjusted to the canine-protected occlusion and cemented with glass ionemer cement (Meron, Voco, Cuxhaven, Germanyl in order to increase retention of dentures against short clinic crowns (Figure 4).

Recall evaluations at 6-month intervals occurred for a period of 1 year, and the patient did not experience tooth sensitivity or any other

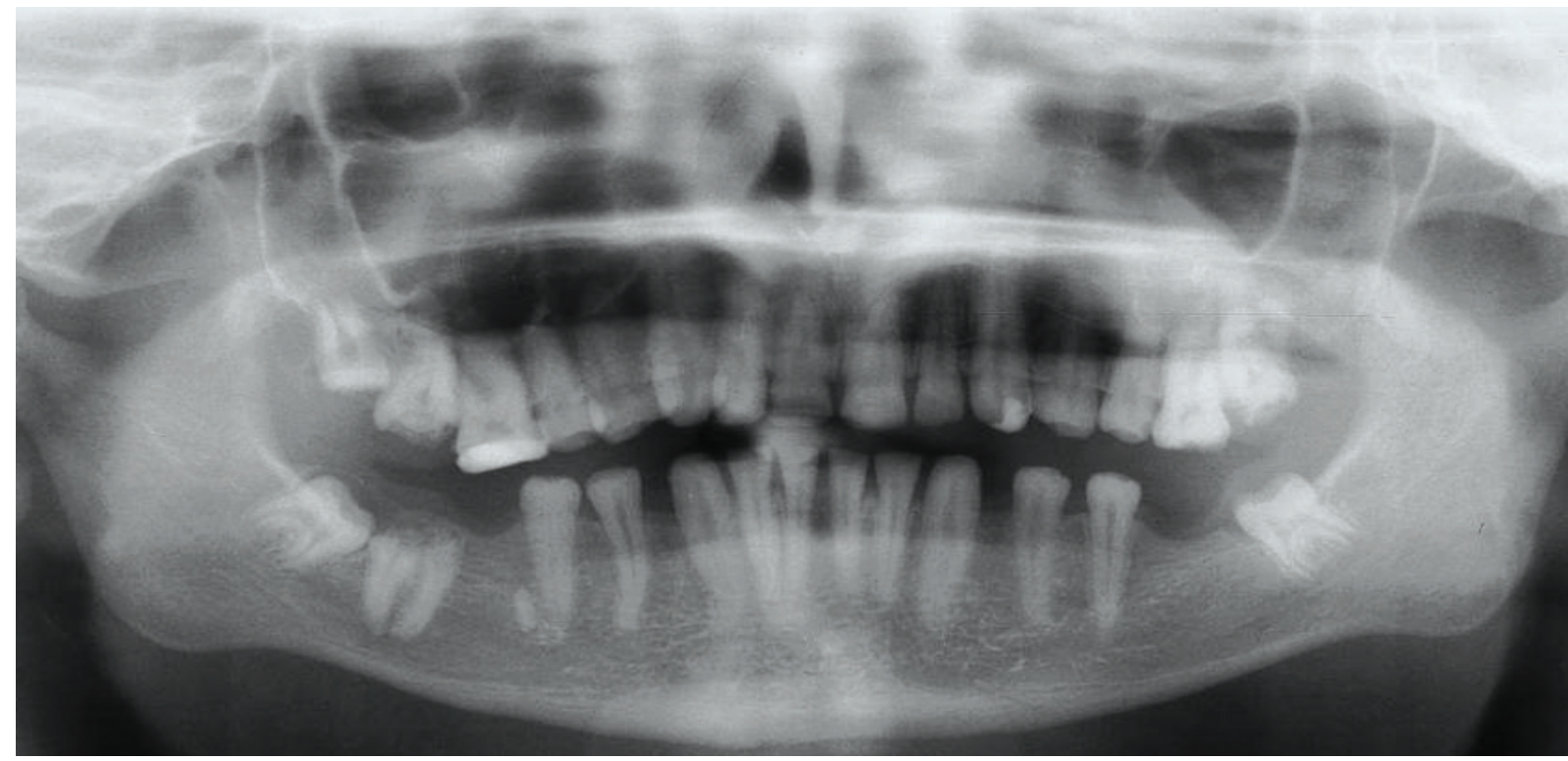

Figure 3. Panoramic radiograph of patient after 1 year.

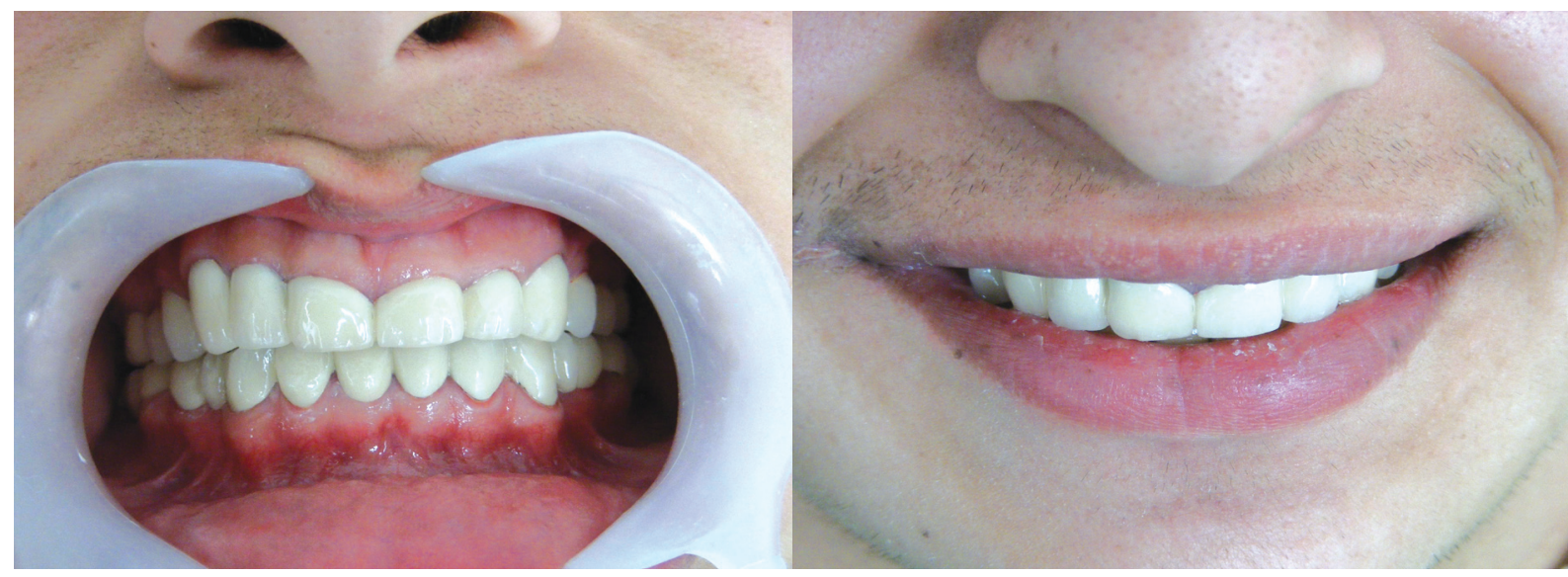

Figure 4. Intraoral and extraoral views of the prostheses. 
complication associated with the oral rehabilitation. The patient's esthetic and functional expectations were also satisfied.

\section{DISCUSSION}

In patients without $\mathrm{Al}$, crown resorption is a rare but very striking, usually asymptomatic, clinical entity, which is discovered only as incidental radiographic finding. ${ }^{13}$ Crown resorption of unerupted teeth may be observed in patients with $\mathrm{Al}$ as in our case. Collins et $\mathrm{al}^{4}$ found significantly higher crown resorptions in individuals with Al with respect to control group. Also in literature, occlusal resorption of enamel and dentine was identified in Ruston's case of hereditary enamel hypoplasia. ${ }^{14}$ Active resorption in the crowns of unerupted teeth was reported in two siblings affected by autosomal recessive $\mathrm{Al}^{15}$ and considerable crown resorption was described by Williams and Ogden. ${ }^{16}$ In this process the etiology has been remained unclear, although several theories such as occult caries, periapical inflammation of a primary precursor causing epithelial disruption of the succeeding permanent tooth, idiopathic external resorption, and developmental defect due to an inclusion of uncalcified enamel matrix were proposed. ${ }^{17}$ The defects in this case were unlikely to be resulted from caries because they were already present before eruption. They were more likely to be resorptive lesions commencing after tooth crown development. It is possible that this situation may have arisen as a result of abnormalities in the follicles.

The prosthetic rehabilitation of Al patients has been previouslypresented in severalcasereports. ${ }^{18-}$ ${ }^{21}$ The clinician must carefully balance the esthetic needs of the patient, strength of the restoration, protection of the remaining teeth, and long-term prognosis of the treatment. Treatment planning for patients with amelogenesis imperfecta is related to many factors: the age and socioeconomic status of the patient, the type and severity of the disorder, and the intraoral situation at the time the treatment is planned. ${ }^{18}$ Due to poor socioeconomic status, the patient refused all ceramic restorations. Therefore, in the present case, porcelain fused to a precious metal alloy approach was utilized for the restoration of the teeth. Both the marginal fit and the color acceptability of the restorations were satisfactory. Patients and dentists should discuss the advantages and disadvantages of treatment options in deciding the best treatment plan.

Management of amelogenesis imperfecta using fixed prosthodontics in the young adults is not a novel approach, but is possibly an underutilized one. ${ }^{19}$ The selected fixed prosthodontic treatment, albeit invasive, was more conservative than other considered alternatives. Other treatment methods involving extractions of remaining teeth and placement of removable prostheses or extractions of remaining teeth combined with implantsupported fixed or removable prosthodontics were considerablymoreradicaland had greaterincidence of clinical complications than conventional fixed and removable prosthodontics. ${ }^{20-21}$ This patient wished to retain his natural dentition as much as possible.

\section{REFERENCES}

1. Lykogeorgos T, Duncan K, Crawford PJ, Aldred MJ. Unusual manifestations in X-linked amelogenesis imperfecta. Int $J$ Paediatr Dent 2003;13:356-361.

2. Crawford PJ, Aldred MJ.X-linked amelogenesis imperfecta. Presentation of two kindreds and a review of the literature. Oral Surg Oral Med Oral Pathol 1992;73:449-455.

3. Neville BW, Damm DD, Allen CM, Bouquot JE. Oral and Maxillofacial Pathology. Philadelphia: WB Saunders Company. 1995; p. 79-84.

4. Collins MA, Mauriello SM, Tyndall DA, Wright JT. Dental anomalies associated with amelogenesis imperfecta: a radiographic assessment. Oral Surg Oral Med Oral Pathol Oral Radiol Endod 1999;88:358-364.

5. Macedo GO, Tunes RS, Motta AC, Passador-Santos F, Grisi MM, Souza SL, Palioto DB, Taba M Jr, Novaes AB Jr. Amelogenesis imperfecta and unusual gingival hyperplasia. J Periodontol 2005;76:1563-1566.

6. Peters E, Cohen M, Altini M. Rough hypoplastic amelogenesis imperfecta with follicular hyperplasia. Oral Surg Oral Med Oral Pathol 1992;74:87-92.

7. Nakata M, Kimura O, Bixler D. Interradicular dentin dysplasia associated with amelogenesis imperfecta. Oral Surg Oral Med Oral Pathol 1985;60:182-187.

8. Korbmacher HM, Lemke R, Kahl-Nieke B. Progressive pre-eruptive crown resorption in autosomal recessive generalized hypoplastic amelogenesis imperfecta. Oral Surg Oral Med Oral Pathol Oral Radiol Endod 2007;104:540544. 
9. Price JA, Wright JT, Walker SJ, Crawford PJ, Aldred MJ, Hart TC. Tricho-dento-osseous syndrome and amelogenesis imperfecta with taurodontism are genetically distinct conditions. Clin Genet 1999;56:35-40.

10. Aldred MJ, Savarirayan R, Lamandé SR, Crawford PJ. Clinical and radiographic features of a family with autosomal dominant amelogenesis imperfecta with taurodontism. Oral Dis 2002;8:62-68.

11. Gertzman GB, Gaston G, Quinn I. Amelogenesis imperfecta: local hypoplastic type with pulpal calcification. J Am Dent Assoc 1979;99:637-639.

12. Ravassipour DB, Powell CM, Phillips CL, Hart PS, Hart TC, Boyd C, Wright JT. Variation in dental and skeletal open bite malocclusion in humans with amelogenesis imperfecta. Arch Oral Biol 2005;50:611-623.

13. Johnson M, Harkness M. Pre-eruptive coronal radiolucency in a mandibular premolar: a case report and literature review. $N Z$ Dent $J$ 1997;93:84-86.

14. Rushton MA. A case of hereditary enamel hypoplasia. $\mathrm{Br}$ Dent $J$ 1950;88:300-301.

15. Wright JT. Analysis of kindred with amelogenesis imperfecta. J Oral Pathol 1985;14:366-374.

16. Williams SA, Ogden AR. Failure of eruption associated with anomalies of the dentition in siblings. Pediatr Dent 1988;10:130-136.

17. Savage NW, Gentner M, Symons AL. Preeruptive intracoronal radiolucencies: review and report of case. ASDC J Dent Child 1998;65:36-40.

18. Sari T, Usumez A. Restoring function and esthetics in a patient with amelogenesis imperfecta: a clinical report. $J$ Prosthet Dent 2003;90:522-527.

19. Mink JR, Okeson JP. Fixed prosthodontics for the young adolescent. In: Goldman HM. Current therapy in dentistry. Vol VI. St. Louis: Mosby; 1977. p. 493-503.

20. Coley-Smith A, Brown CJ. Case report: radical management of an adolescent with amelogenesis imperfecta. Dent Update 1996;23:434-435.

21. Goodacre CJ, Guillermo B, Rungcharassaeng, Kan JYK. Clinical complications with implants and implant prostheses. J Prosthet Dent 2003;90:121-132. 